\title{
Ipostaze morfologice ale formei veri în (daco)româna veche
}

\author{
Andreea Dinică \\ Institutul de Lingvistică „Iorgu Iordan - Al. Rosetti”, Calea 13 Septembrie 13, 050711 București, România
}

\section{Despre articol \\ Istoric:}

Primit 27 iunie 2017

Acceptat 22 iulie 2017

Publicat 30 septembrie 2017

Cuvinte-cheie: gramaticalizare verb predicativ verb auxiliar conector disjunctiv conector concesiv

\begin{abstract}
Rezumat
În dacoromâna veche, veri < lat. velis are diferite valori morfologice, de la valoarea primară, cea de verb predicativ (veri - a vrea, $2 \mathrm{sg}$ ), la verb auxiliar (veriface), conjuncție sau element component al unui conector disjunctiv (veri ... veri), respectiv concesiv (să veri că), formant al indefinitelor (vericine, vericît etc.). Evoluția de la valoarea verbală la celelalte tipuri este rezultatul unui proces de gramaticalizare identificat nu numai în română, unde continuă tendința începută în latina tîrzie, ci și în alte limbi, neînrudinte genealogic, dintre care sugestivă pentru comparație este albaneza. Scopul acestui articol este inventarierea și exemplificarea ocurențelor formal-funcționale ale lui veri, bogat atestate de timpuriu în română.
\end{abstract}

\section{Preliminarii}

Forma veri aparține paradigmei verbului a vrea (voi(u), veri/vei, va, vrem(i)/văm(u)/vom(u), vreți/veți, vor $(u))$, verb ${ }^{1}$ care a avut iniţial o singură paradigmă de indicativ prezent, atît ca verb predicativ, cît și ca auxiliar. Provine din lat. velis, forma de subjonctiv, persoana a doua singular, care ia locul în latina tîrzie formei de indicativ clasic vis. Veri este prima fază, cea mai arhaică, a evoluției pe teren românesc a lat. velis. Ulterior, evoluția fonetică a lui veri ia două direcții diferite, în funcție de ipostaza în care se gramaticalizează: veri evoluează fonetic la vei (forma disponibilă în limba actuală) ocurent exclusiv ca auxiliar, în timp ce, în ipostaza de formant proclitic al indefinitelor, veri- evoluează la ori-. Reflexele fonetice diferite indică faptul că procesele de gramaticalizare au fost diferite, începute încă din latină (Ernout \& Meillet, 1959, s.v. quis), manifestate și în limbile balcanice (Sandfeld, 1930), ca urmare a unei tendințe tipologice mai ample (Haspelmath, 1997). Trebuie remarcat că, încă din primele texte păstrate în limba română, atît forma arhaică veri, cît și inovațiile ulterioare vei și ori-coexistă, raportul dintre forme fiind diferit, în funcție de perioadă, de zona geografică din care provine textul, de tipul de text.

\section{Ipostazele morfologice ale formei veri}

În cele mai vechi texte românești, veri apare ca verb predicativ ( $\$ 2.1)$, auxiliar $(\$ 2.2)$, conector $(\$ 2.3)$ disjunctiv (\$2.3.1) sau element din structura unui conector concesiv (\$2.3.2), formant în structura indefinitelor $(\$ 2.4)$.

În cele ce urmează vom analiza doar situațiile în care apare forma arhaică veri, fără a lua în discuție reflexele ulterioare vei și ori-.

\subsection{Verb predicativ}

Veri predicativ este forma arhaică de persoana a doua singular din paradigma verbului a vrea, și este atestată cu această valoare încă din primele texte. Poate apărea în enunțuri independente interogative (1a), negative (1b), în propoziții principale (1c), în diferite tipuri de subordonate, cu precădere condiționale (1d-g), dar şi în alte tipuri $(1 \mathrm{~h}-\mathrm{i})$ :

\footnotetext{
*Adresă de corespondență: andreea.dinica@gmail.com.

${ }^{1}$ Din paradigma verbului a vrea și persoana a treia singular, va, apare în diferite ipostaze morfologice (vezi discuția la Zamfir \& Dinică, 2009).
} 
(1) a. El grăi ei: „Ce veri?” $\left(\mathrm{CC}^{2} .1581,64\right)$

b. Nu veri să răspunzi nemică ce acești pre tine mărturisesc? $\left(\right.$ CC $\left.^{2} .1581,97\right)$

c. Deci tu însuți nu asculți rugăciunea ta, ome, iară Dumnezeu tu veri să o auză. (Cc ${ }^{2} \cdot 1581$, 327)

d. Să veri să mergi în viiață, păzeaște porîncitele $\left(\mathrm{CC}^{2}\right.$.1581, 288)

e. Să veri desfirșit să fii, du-te și vinde avuțiia ta şi dă mișeilor $\left(\mathrm{CC}^{2} .1581,288\right)$

f. Doamne, să veri, poți să mă curățești (CT.1560-1,47)

g. Derept aceaia de veri să mă grăiești dulce, ca Dumnezeu mă grăiaște dulce, $\left(\mathrm{CC}^{2} .1581,433\right)$

h. Că cît veri, tu faci, și al tău cuvînt lucru fi-va, și cuvîntului lucrul ajută. $\left(\right.$ CC $\left.^{2} \cdot 1581,227\right)$

i. fie ție cum veri $\left(\mathrm{CC}^{2} .1581,326\right)$

Cu totul izolat, Zamfir (2005, p. 60) înregistrează în Psaltirea Scheiană forma veri cu valoare de imperativ (2a), valoare stabilită pe baza corespondenței cu versiunile celorlalte psaltiri (2b):

(2) a. Voia rostului mieu dulce veri Doamne, și giudecatelor tale învață-me (Ps.1573-8, 409)

b. Voia rro<stu>lui mieu iubeaște, Doamne, și dziselor tale învață-me (PH.1500-10, 106 $)$

\subsection{Auxiliar}

În faza veche a dacoromânei, formele de indicativ prezent din paradigma verbului a vrea funcționau atît ca verb predicativ, cît și ca auxiliar. Veri apare ca auxiliar (gramaticalizat) al viitorului (3), în antepoziție $(3 a, b)$ sau în postpoziție $(3 c-e)$ și intră în structura perifrazei de viitor de tipul voi + conjunctiv $(4 a-c)$ :

(3) a. Cîndu veri veni cătră mine? (Ps.1573-8, 323)

b. se venci căndu veri giudeca (Ps.1573-8, 159)

c. Chiamă-mă în dzi de grija ta și izbăvi-te-voiu şi proslevi-me-veri (Ps.1573-8, 156)

d. Învățătoare, vrea-veri de ce te vrem ceare să faci noao? (CT.1560-1, 139 $)$

e. Închina-te-veri Domnului Dumnezeul tău și aceluia unuia sluji-veri (Ст.1560-1, 120 )

(4) a. veri să dai samă înaintea Domnului (șT.1652, 189)

b. tu însuți ești aicea venit și veri să biruiești (Po.1582, 60)

c. Și veri să facem trei cămări, ție una, și lu Moisi una și una lu Ilie $($ Ст.1560-1, 137v)

Statutul formei veri în exemplele de sub (4) este ambiguu. Din cauza nuanței puternic volitive, este greu de precizat dacă este vorba de verbul predicativ în curs de gramaticalizare sau de o formă deja gramaticalizată, cu toate că prima ipoteză este mai viabilă, dacă admitem că tipul modern de viitor $o$ să fac provine din tipul voi + conjunctiv (Zamfir, 2007, p. 225).

În privința viabilității în timp a lui veri (atît predicativ, cît și auxiliar) și a distribuției regionale, analizînd exhaustiv numărul ocurențelor în corpusul de texte, Zamfir (2005, p. 61-65) distinge, în prima jumătate a secolului al XVII-lea, două arii dialectale net opuse-forma etimologică veri era încă forma viabilă în Moldova, în timp ce în Transilvania de sud-vest se generalizase vei. În cea de-a doua jumătate a secolului al XVII-lea, concluzia statistică a investigației textelor este că uzul lui veri se reduce considerabil.

\subsection{Conector}

În calitate de conector, apare ca disjunctiv $(\$ 2.3 .1)$ în structuri corelative sau ca element din structura unui conector concesiv (\$2.3.2). 


\subsubsection{Conector disjunctiv}

Inventarul de conectori disjunctivi în structuri corelative în dacoromâna vehe este mai bogat decît cel din limba actuală—pe lîngă structurile care implică conectori care persistă și în româna contemporană (sau ... sau, fie ... fie, ori ... ori) apar, pe tot parcursul perioadei, și alți conectori: au ... au, oare ... oare, vare ... vare, veri ... veri, săva(i) ... săva(i) (Densusianu, 1997, p. 620-621; Frâncu, 2009, p. 148; Croitor, 2016, p. 449-450), cu frecvențe diferite, dar distribuție identică (6a-c).

Structurile corelative disjunctive apar cu precădere în pravile și documente, în tipare de construcție care presupun menționarea unui tip generic și apoi enumerarea setului (cel mai adesea exhaustiv) de posibilități:

(5) acela se va certa ... de-ar fi orice feliu de om, ver fie mirean, veri călugăr, ver fiece om în clirosul besearecii (Prav.1652, 139)

Specific tiparelor cu disjuncție corelativă în textele din dacoromâna veche este variația conectorului în interiorul aceleiași serii:

(6) a. să strîngă pă toți rumânii de la sat ... oricarii pă unde să vor afla fugiți ... ori în sat domnescu, veri în sat boierescu, au în călugărescu, au la slobozii, veri la tîrguri (DRH,B.1635, 110)

b. se vr-un frate numeaște-se vare curvariu, vare hasnă-luotoriu, sau drăceaște slujitoriu sau pîrî uritoriu [...] cu aceia se nu mîncați (Св.1559-60, 391-2)

c. oare moșul cū nepotul săva doi frațî a se împreuna cu mîtușe micîși cu nepoata-i (Prav.1581, $\left.266^{\mathrm{v}}\right)$

Variația conectorilor apare adesea în cadrul aceluiași text, astfel că nu se poate stabili preferința pentru unul sau altul dintre conectori decît pe baza unei statistici riguroase.

Un tipar sintactic asimetric în care apare veri corelativ cuprinde, ca prim element, o structură propozițională $(7 \mathrm{a}-\mathrm{f})$ în care verbul este la moduri și timpuri care au ca trăsătură irealul, posibilul, trăsăturile fundamentale ale disjuncției în limbile naturale (Zafiu, 2012): conjunctiv ( $7 \mathrm{a}-\mathrm{c})$, condițional (7d), viitor $(7 \mathrm{e}, \mathrm{f})$, urmat de setul de alternative, realizate prin structuri eliptice, în care se pătrează elementele relevante la nivelul informației [numele predicative în $(7 \mathrm{a}, \mathrm{b}, \mathrm{c}, \mathrm{e}, \mathrm{f})$, modificatorii de tip adjectival în $(7 \mathrm{~d})$ ]:

(7) a. cine va fi arat ... veri fie turcu, veri călăraș, veri sîrb, veri țăran, de la tot omul să ia dijma (DRH,B.1635-1636, 341)

b. veri fie muiare, veri fată $(s ̦ T .1652,277)$

c. Iară de va fi nevoie, să fie pruncul spre moarte, să-l boteadze ori în ce ceas vor chema preotul, veri fie noapte, veri dzuo (șT.1652, 28)

d. să-l caute, să-l prinză, veri să l-ar afla în țigănie domnească, veri boerească, veri călugărească (DRH,B.1635-1636, 348)

e. veri va fi mare, veri mic, veri mult, veri puțin (Prav.1646, 68)

f. acesta, ver va fi bărbat ver muiare, cu moarte să să certe (Prav.1646, 127)

Forma de conjunctiv fie din $(7 \mathrm{a}, \mathrm{b})$, care are în aceste contexte valoare verbală, probată de tiparele $(7 \mathrm{~b}-\mathrm{d})$, este forma care se va gramaticaliza drept conector disjunctiv, prin slăbirea treptată a lui veri.

În cadrul tiparului corelativ disjunctiv simetirc, veri poate introduce diferite tipuri de grupuri sintactice: grupuri nominale $(8 \mathrm{a})$, adjectivale $(8 \mathrm{~b}, \mathrm{c})$, prepoziţionale $(8 \mathrm{~d}-\mathrm{g})$, adverbiale $(8 \mathrm{~h})$, sau structuri propoziționale $(8 \mathrm{i})$ :

(8) a. Oricare mirean, veri bărbat, veri muiare, dacă va mearge la beserică fie la ce slujbă, veri vecernie, veri la itros, veri la ceasuri, veri la Svinta Liturghie (șT.1652, 104)

b. carele va găsi pre marginea unii ape mari, fie ce lucru, ver mare, ver mic, carile va fi aruncat apa ca o plavie (Prav.1646, 69) 
c. veri tînăr veri bătrîn i să va tăia capul (Prav.1646, 163)

d. preotul de va fi oprit de liturghie, veri cu vină, veri fără de vină (șT.1652, 130)

e. cine o va rușina veri cu voe veri fără voia ei (Prav.1646, 136)

f. să picnească dencătro i va fi voia, veri în mijloc, veri de lături (DRH,B.1646, XXXI, 143)

g. Iar cine se va ispiti a sparge această tocmeală a noastră, veri den feciorii noștri, veri den rudele noastre, acela să fie proclet (DRH,B.1635, 26)

h. cela ce va găsi ceva mărgînd pă drum, fie ce va fi, veri mult, veri puțin (Prav.1646, 68)

i. Iară de va fi neștine de 30 de ai veri aibă feciori, veri nu aibă, să nu se cuminece (șT.1652, 249)

În mod cu totul izolat, în tot corpusul de texte păstrate din epoca veche și cercetate pînă acum apar cîteva atestări ale formei să veri cu valoare disjunctivă (scris în unele cazuri fie cu, fie fără pauză grafică):

(9) a. Derept aceaia plecați-vă a toată deregătoria omenească pentru Domnul: săveri luĭ craĭu ca ūnuĭ mai mare, să veri deregătorilor, ca trimișilor de la dinsu. (NT.1648, 183v)

b. oricine va îndrăzni pentru treaba lui de va lua ceva, vreun vas den beserică, să veri măhramă au vreo poală de icoană, sau discos sau altă ceva aseamenea acestora, și noi după canonul Svinților Apostoli punem afurisenie asupra lor (șT.1652, 161)

Formal, să veri este analogic cu săva (să urmat de persoana a treia, va, din paradigma verbului a vrea), ocurent mult mai frecvent ca disjunctiv (Zamfir \& Dinică, 2009).

În (9a), să veri formează o pereche corelativă, chiar dacă și la mică distanță apar fluctuații în ceea ce privește grafia lui, în timp ce în (9b) introduce un singur element al setului enumerat (să veri măhramă) și intră în corelație cu sau.

\subsubsection{Formant în structura conectorului concesiv}

Să veri că, analogic formal conectorului concesiv săva(i) că (discutat pe larg în Zamfir \& Dinică, 2009) este atestat, din corpusul cercetat de noi, numai în NT.1648:

(10) a. Și pentru că nu le putea asămăna că le părea că grăiaște împrotivâ ūna alțiiia iarâ èi lepăda cartea luĭ Ĭacov din cărțile sfinte. Să veri cằ bine să tocmescă numaĭ să socotiți bine, că nu grăesc amăndoi di ūn feal de credințâ și de ūn feal de îndereptătură. (NT.1648, 174 ${ }^{\mathrm{r}}$ )

b. cum s-au ferit și êl de n-au luat platâ, să ver că-ĭ ēra slobod (NT.1648, 223 $3^{\text {r }}$

c. Ĭarâ deaca veniiu în Trōada a propovedui Evangheliia lư̆ Hristos, să ver că- mī èra mie poarta deșchisâ pren Domnul, nu avuiu răpao sufletuluı̆ mieu. (NT.1648, 241 ${ }^{\mathrm{v}}$ )

Numărul de atestări ale lui să veri că în ansamblul românei vechi este nesemnificativ, dar această creație analogică ad-hoc este sugestivă pentru cumulul de sensuri și funcții ale lui veri în textele epocii.

\subsection{Formant în structura nehotărîtelor}

Evoluția formelor din paradigma verbului a vrea către conjuncții disjunctiv-concesive și marcatori în structura indefinitelor este recognoscibilă la nivel tipologic (Haspelmath, 1997). În română, textele disponibile nu surpind procesul de gramaticalizare, deja încheiat în faza din care datează cele mai vechi atestări scrise, dar exemple ca (11) dau un indiciu asupra sensului trecerii de la conector corelativ disjunctiv la marcator de indefinitudine:

(11) nici un datornic, veri turcu, veri neguțătoriu, verice feliu de om va fi, nimenilea treabă cu Radul logofătul să n-aibă, nice cu zestrele jupînesei lui, veri sat, veri țigani, veri dobitoc, veri ce va avea Radul logofătul (DRH,B.1636, XXV, 470) 
În tiparul specific în care apare corelativul disjunctiv veri de indicare a termenului general (zestrele jupînesei, în exemplul 11) și enumerare a posibilităților lui de materializare (sat, țigani, dobitoc), ultimul element este actualizat printr-o propoziție relativă (ce va avea Radul logofătul). În structurile de acest tip, conectorul se ataşează elementului relativ și formează serii de indefinite care apoi vor funcționa și independent de contextele primare, disjunctive din care provin.

Textele furnizează numeroase exemple, în care gradul de sudare al conectorului-marcator de indefinitudine este variabil:

(12) a. Iar de va vrea cineva din rudele mele, veri cine va fi, să ia acești țigani (DRH,B.1635, XXV, 75)

b. să aibă a luoare dijmă de pre toată ocina sventei monastiri și de la cîmpu ... și de la tot omul, care se va hrăni pre ocina mănăstirii, veri cu ce se vor hrăni (DRH,B.1635, XXV, 99)

c. am vîndut 3 pogoane de țelină au la Gruiu, au la Sperlea, veri unde le va plăcea dumnealor (DRH,B.1646, XXXI, 273)

d. viile de la Copăcel cu rumânii și cu tot venitul, vericît să va alege (DRH,B.1635, XXV, 83)

e. partea de moșie a tătîne-nostru vericîtă să va afla în sat (DRH,B.1635, XXV, 93)

f. carii deîntru feciorii noștri, au deîntru rudeniile nostre, au deîntr-alt neam se va ispiti veri cînd a sparge și a strica această tocmeală (DRH,B.1635, XXV, 97)

g. de să vor și ridica vericînd (DRH,B.1645, XXX, 323)

Pentru gradul de sudură variabil, procesul de gramaticalizare incomplet și cumulul de funcții ale lui veri sînt relevante situațiile din exemplul (12b), care prezintă o formă la limita între verb propriu-zis, conjuncție disjunctivă și marcator de indefinitudine.

\section{Concluzii}

În articolul de față, am exemplificat tipurile de ocurențe și direcțiile de evoluție ale uneia dintre cele mai longevive forme etimologice (apar atestări pînă în secolul al XIX-lea) din paradigma verbului a vrea. Cu valoare verbală, veri apare frecvent încă din primele texte în concurență cu varianta secundară din punct de vedere fonetic vei, iar ca element conector disjunctiv-concesiv și marcator de indefinitudine este, în această perioadă, mult mai frecvent decît dubletul său ori. Conector specific tiparelor fixe din pravile și documente, este concurat de alţi conectori din inventarul foarte bogat disponibil în perioada discutată. Viabilitatea lui de-a lungul a trei secole și dispariția abruptă din româna actuală sînt datele unei schimbări ciclice (van Gelderen, 2016) cu caracter universal. Polifuncționalitatea formei veri este specifică și altor elemente din româna veche (v. Vasilescu, 2017, în acest volum).

\section{Bibliografie}

\section{A. Corpus}

св.1559-60 = Codicele Bratul, ed. Al. Gafton, Iaşi, 2003, [online].

$\mathrm{CC}^{2} .1581$ = Coresi, Evanghelie cu invuățătură, în Carte cu invaățătură (1581), vol. I, Textul, ed. S. Pușcariu \& Al. Procopovici,

Atelierele Grafice Socec, București, 1914.

Ст.1560-1 = Coresi, Tetraevanghel, în Tetraevanghelul tipărit de Coresi, Braşov 1560-1561, comparat cu Evangheliarul lui

Radu de la Mănicești. 1574, ed. Fl. Dimitrescu, Editura Academiei, București, 1963.

DRH,B = Documenta Romania Historica. B. Țara Românească, Editura Academiei Române, București, 1974: vol. XXIV (1633-

4); 1985: vol XXV (1935-1936), 1998: vol. XXXI (1645).

NT.1648 = Noul Testament, Editura Reîntregirea, Alba Iulia, 1998.

PH.1500-10 = Psaltirea Hurmuzaki, ed. I. Gheție \& M. Teodorescu, Editura Academiei Române, București, 2005.

po.1582 = Palia de la Orăștie, ed. V. Pamfil, Editura Academiei, București, 1968.

Prav.1581 = Pravila ritorului Lucaci, 1581, ed. I. Rizescu, Editura Academiei, București, 1971.

Prav.1646 = Carte românească de invvățătură, 1646, ed. A. Rădulescu, Editura Academiei, București, 1961.

Prav.1652 = Îndreptarea legii, 1652, ed. A. Rădulescu, Editura Academiei, București, 1962. 
Ps.1573-8 = Psaltirea Scheiană comparată cu celelalte psaltiri din secolele al XVI-lea și al XVII-lea, ed. I.-A. Candrea, Socec, București, 1916; Psaltirea Scheiană, ed. I. Bianu, Carol Göbl, București, 1889.

ȘT.1652 = Șeapte taine a besearecii, Iași, 1644, ed. I. Mazilu, Editura Universității „Alexandru Ioan Cuza”, Iași, 2012.

\section{B. Referințe}

Croitor, B. (2016). Coordination and coordinating conjunctions, în Pană Dindelegan, G. (ed.), The Syntax of Old Romanian, Oxford University Press, Oxford, Crossref.

Densusianu, O. (1997). Historie de la langue roumaine, I. Les origines, II. Le seizième siècle, Ediție critică și note de V. Rusu, Prefață de B. Cazacu, Editura „Grai și Suflet - Cultura Națională”, București.

Ernout, A. \& Meillet, A. (1959). Dictionnaire Étymologique de la Langue Latine, Klincksieck, Paris.

Frâncu, C. (2009). Gramatica limbii române vechi (1521-1570), Casa Editorială Demiurg, Iași.

Haspelmath, M. (1997). Indefinite Pronouns, Clarendon Press, Oxford.

Sandfeld, Kr. (1930). Linguistique balkanique. Problèmes et résultats, Librairie Ancienne Honoré Champion, Paris.

van Gelderen, E. (ed.) (2016). Cyclical Change Continued, John Benjamins Publishing Company, Amsterdam, Crossref.

Vasilescu, A. (2017). Evoluția descendenților lui ipse în limba română, în „Diacronia”, nr. 6, 30 sept., art. A87, Crossref.

Zafiu, R. (2012). Conectorii disjunctivi din perspectivă semantico-pragmatică: ipoteze asupra proceselor de gramaticalizare, în „Limba română”, vol. LXI, nr. 3, p. 417-428.

Zamfir, D.-M. (2005). Morfologia verbului în dacoromâna veche (secolele al XVI-lea - al XVII-lea), vol. I, Editura Academiei Române, București.

Zamfir, D.-M. (2007). Morfologia verbului în dacoromâna veche (secolele al XVI-lea - al XVII-lea), vol. II, Editura Academiei Române, București.

Zamfir, D.-M. \& Dinică, A. (2009). Quelques cas de grammaticalisation des formes flexionnelles du verbe a vrea «vouloir» en vieux daco-roumain: les conjonctions et locutions conjonctionnelles disjonctives et concessives (să) veri (că) «ou; soit; soit même; bien que», săva(i) (că) «idem», comunicare în cadrul colocviului Grammaticalization and Pragmaticalization in Romanian, Universitatea din București, 3-4 octombrie 2008. 